\title{
Neurochemical sex differences in adult ADHD patients: an MRS study
}

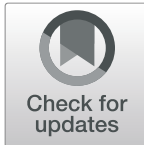

\author{
Dominique Endres ${ }^{1,2^{*}}$, Ludger Tebartz van Elst ${ }^{1,2}$, Simon J. Maier ${ }^{1,2}$, Bernd Feige ${ }^{1,2}$, Peter Goll ${ }^{1,2}$, Simon A. Meyer ${ }^{1,2}$, \\ Swantje Matthies ${ }^{2}$, Katharina Domschke ${ }^{2}$, Thomas Lange ${ }^{3}$, Esther Sobanski ${ }^{4,5}$, Alexandra Philipsen ${ }^{6}$, \\ Kathrin Nickel ${ }^{1,2+}$ and Evgeniy Perlov ${ }^{1,2,7 \dagger}$
}

\begin{abstract}
Objective: Attention-deficit/hyperactivity disorder (ADHD) is a common neurodevelopmental disorder. Relevant sex differences in symptomatology are discussed. This study compared brain neurometabolism in the anterior cingulate cortex (ACC) and left cerebellar hemisphere in age- and IQ-matched adult male (mADHD) and female (fADHD) ADHD patients.

Methods: We studied 48 (ACC) and 42 (cerebellum) male/female pairs of stimulant-free patients with adult ADHD. Single voxel magnetic resonance spectroscopy (MRS) was used to investigate creatine (Cre), total choline (t-Cho), glutamate + glutamine (G|x), N-acetylaspartate, and myo-inositol. The mADHD and fADHD groups were compared using robust linear regression. The level of significance was corrected for multiple tests using the BenjaminiHochberg approach.

Results: For the ACC, the signals of Cre $(p=0.008)$ and t-Cho $(p=0.004)$ showed significant effects of the age covariate as well as an interaction of sex and age (Cre: $p=0.033$; t-Cho: $p=0.040$ ). For the Glx signal, an interaction of sex and age could also be observed $(p=0.033)$. For cerebellar neurometabolites, the signals of t-Cho $(p=0.049)$ and $\mathrm{Glx}(p=0.049)$ showed significant effects of the factor sex.

Conclusion: This is the largest study yet to analyze sex differences in brain neurochemistry in adult patients with ADHD. Different age-dependent t-Cho signals in the ACC might be associated with delayed myelinization in mADHD. Further MRS studies in adult ADHD, accounting for possible sex effects, are warranted to validate the present findings.
\end{abstract}

Keywords: ADHD, MRS, Sex, Choline, Anterior cingulate cortex, Cerebellum

\section{Introduction}

Attention-deficit/hyperactivity disorder (ADHD) is the most frequently diagnosed neurodevelopmental disorder, with prevalence rates of $3-5 \%$ in childhood $[19,31]$. The prevalence rates in adulthood are estimated to be 1.43.6\% [18]. The core symptoms of ADHD are inattention and hyperactivity combined with impulsivity, emotional instability, disorganized behavior, impaired affect control, and emotional hyper-reactivity [14, 19, 31, 42]. For a long

\footnotetext{
*Correspondence: dominique.endres@uniklinik-freiburg.de

${ }^{\dagger}$ Kathrin Nickel and Evgeniy Perlov are shared last authors.

'Section for Experimental Neuropsychiatry, Department of Psychiatry and Psychotherapy, Medical Center-University of Freiburg, Faculty of Medicine, University of Freiburg, Freiburg, Germany

${ }^{2}$ Department of Psychiatry and Psychotherapy, Medical Center-University of Freiburg, Faculty of Medicine, University of Freiburg, Freiburg, Germany Full list of author information is available at the end of the article
}

time, the disease was considered to be mainly a male disorder, possibly due to the high (4:1) ratio of male ADHD (mADHD) to female ADHD (fADHD) [58] and the predominant and striking symptoms of hyperactivity and impulsivity in young boys [48]. The sex difference in incidence vanishes in adulthood, with a ratio of $\mathrm{mADHD}$ to fADHD of close to 1:1 [58].

\section{The pathophysiology of ADHD}

The dopaminergic and noradrenergic systems seem to play a central role in the pathophysiology of ADHD $[6,42]$. The hypothesis that a dopaminergic (and noradrenergic) deficit plays a role in ADHD is supported by the effectiveness of methylphenidate in treating the condition [58]. Dopamine closely interacts with the glutamate system. Glutamate (Glu) can directly activate dopaminergic 
neurons (the "accelerator system") and indirectly activate $\gamma$-aminobutyric acid (GABA) neurons and inhibit dopaminergic neurons (the "brake system") to create a homeostatic equilibrium of cortical-subcortical excitation and inhibition $[8,9,37,55]$. Investigations of the genes involved in GABA and Glu transmission have provided evidence that altered GABAergic and glutamatergic transmission may lead to modification of the cortical excitatory and inhibitory balance in ADHD [36]. At a structural level, a dysfunction of the frontostriato-thalamo-frontal circuits has been implicated in the pathogenesis of ADHD [38].

\section{Magnetic resonance spectroscopy}

Single voxel proton spectroscopy (SVS) allows absolute quantification of Glu and glutamine (Gln) $(\mathrm{Glu}+\mathrm{Gln}=$ Glx), phosphorylcholine plus glycerylphosphorylcholine (total choline: $\mathrm{t}$-Cho), $\mathrm{N}$-acetylaspartate (NAA), creatine (Cre), and myo-inositol (mI). For the non-invasive detection of these neurometabolites, the SVS magnetic resonance spectroscopy (MRS) technique uses the nuclear magnetic resonance properties of protons to generate a frequency spectrum in which various metabolites can be identified and quantified by their chemical shift along the frequency axis [50]. Glu is the major excitatory neurotransmitter in the human brain. The $\mathrm{t}$-Cho signal represents cell membrane turnover, and Cre is a marker of brain energy metabolism. NAA signals are regarded as indicators of general neuronal integrity, and $\mathrm{mI}$ is a glial marker and part of the phosphatidylinositol second-messenger system [50]. Thus, MRS provides broad insights into cerebral neurometabolism and neuronal health.

\section{Previous MRS findings in ADHD}

So far, more than 30 MRS studies of ADHD have been conducted. In a recent paper, we presented an overview and summary of the first 32 studies [15]. In a previous meta-analysis by our group, we found an increase in the t-Cho signal in the striatum and right frontal lobe of children with ADHD and in the bilateral pregenual ACC (pACC) of adults with ADHD [38]. In a second meta-analysis, the authors reported increased NAA concentrations in the medial prefrontal cortex of children with ADHD but no anomalies in adults with ADHD [1]. So far, only one study has investigated neurometabolic sex differences in children with ADHD, and it found lower NAA signals in the right frontal white matter of girls suffering from ADHD [61]. To date, no studies have been conducted on sex differences in adult patients with ADHD.

\section{Rationale for our study}

In the previous MRS studies of our research group, while we took great care to match patient and control groups with respect to sex, we did not specifically account for sex effects. However, in a recent paper by our group, we reported neurometabolic sex differences in the cerebellum in healthy adult control subjects [16]. Given this observation, we went back to ask whether there might be sex effects in adult patients with ADHD [15]. The clinically observed sex differences in ADHD are poorly understood neurobiologically. Thus, the aim of our study was to compare, for the first time, the neurometabolism of matched adult mADHD and fADHD patients. Drawing on the results of the only comparable previous study in children to date [61], we hypothesized that there would be sex-based differences in NAA signals (confirmatory hypothesis). In an exploratory approach, we furthermore expected distinctive neurochemical profiles in matched mADHD and fADHD patients according to their individual clinical profiles.

\section{Participants and methods Participants}

The patients were recruited as part of a larger, government-funded project called the COmparison of Methylphenidate and PsychotherApy Study (COMPAS) $[15,24,34,39,41,43,56]$. Prior to beginning the study, approval from the local ethics committee was obtained (Faculty of Medicine, Freiburg University, 217/06). The study was registered by Current Controlled Trials (ISRCTN54096201; date applied: 19 October 2006; http://www.isrctn.com/ISRCTN54096201?q=ISRCTN54 096201\&filters $=\&$ sort $=$ \&offset $=1 \&$ totalResults $=1$ \&page $=$ 1 \&pageSize $=10 \&$ searchType $=$ basic-search ) and was conducted according to the ethical principles of the Helsinki Declaration. All the patients gave written informed consent for participation in the MR-imaging project. Only patients from the study centers of Mannheim and Freiburg were included in the imaging study to ensure that the same MRI scanner in Freiburg was used. Experienced senior consultant psychiatrists assessed the patients according to DSM-IV criteria. Only patients without organic causes were included in the study, and all the patients had to be stimulant-free for the past 6 months. Patients with organic diseases (e.g., neurological diseases and hyperthyroidism) that might mimic symptoms of ADHD were also excluded. Psychometric tests included the Conners adult ADHD rating self-report scale: long version (CAARS-S:L) [11] for current ADHD symptoms, the Wender Utah rating scale (WURS-k) $[47,59]$ for ADHD symptoms in childhood, and the Beck depression inventory (BDI) [26] for depressive symptoms. The BDI was collected due to the symptom overlap and common comorbidity of ADHD and depressive symptoms. Premorbid verbal intelligence was assessed by the multiple-choice vocabulary intelligence test [32]. Table 1 provides an 
Table 1 Inclusion and exclusion criteria; according to [15]

$$
\begin{aligned}
& \text { Inclusion criteria } \\
& \text { - Subjects must speak German fluently } \\
& \text { - Aged 18-60 years } \\
& \text { - Diagnosis of ADHD according to DSM-IV criteria } \\
& \text { - A score of > } 30 \text { on the short version of the Wender Utah Rating } \\
& \text { Scale [47] or a clinically validated ADHD diagnosis in childhood } \\
& \text { - Chronic course of ADHD symptoms from childhood to adulthood } \\
& \text { - Subjects provided written informed consent in accordance with } \\
& \text { international guidelines according to the Helsinki Declaration and } \\
& \text { local legislation }
\end{aligned}
$$

- Unobtrusive physical examination (including blood pressure/heart rate) without serious or uncontrolled findings

- Lab results without clinically relevant findings (e.g., blood count, renal retention data, tests of liver function, thyroid parameters)

- ECG and EEG without pathologically relevant results

Exclusion criteria

- $1 \mathrm{Q}<85$ according to the Multiple-Choice Vocabulary Intelligence Test (MWT-B, German version [32])

- Schizophrenia, bipolar affective disorder, borderline personality disorder, antisocial personality disorder, suicidality or self-harm, autism motor tics, Tourette syndrome, or current eating disorder (bulimia nervosa, anorexia nervosa, body mass index <19)

- Substance abuse or dependence in the previous 6 months before the screening. Episodic substance consumption was not an exclusion criterion. A positive drug test during screening.

- Neurological disorders, seizures, pathological EEG results (lateral differences, lesion, epileptiform potentials), glaucoma, diabetes mellitus, fasting blood glucose level $>110 \mathrm{mg} / \mathrm{dl}$, hyperlipidemia, uncontrolled arterial hypertension (according to the guidelines of the German Hypertension Society), angina pectoris, known arterial occlusive disease or other manifestation of vascular disease, known tachycardic arrhythmias, known enlarged prostate, or history of stroke

- Medication with stimulants or ADHD-specific psychotherapy within the previous 6 months before the MRS measurement

- Unwillingness or inability to comply with the requirements of the study protocol

- Inability to understand the nature, significance, and scope of the study

Abbreviations: $A D H D$ attention-deficit hyperactivity disorder, DSM-IV Diagnostic and Statistical Manual of Mental Disorders-Fourth Edition; ECG

electrocardiogram, EEG electroencephalography, IQ intelligence quotient

overview of the inclusion and exclusion criteria. Further reasons for exclusion are presented in Table 2. The diagnostic process has been described in detail in earlier papers $[40,41,43]$. Spectroscopic data were obtained from 187 patients. The quality criteria for inclusion in the automatic matching procedure were fulfilled in 113 patients

\begin{tabular}{|c|c|c|}
\hline \multicolumn{3}{|l|}{244 patients from Freiburg and Mannheim } \\
\hline \multicolumn{3}{|c|}{$\downarrow(\rightarrow 57$ ineligible or not interested in MRI substudy) } \\
\hline \multicolumn{3}{|c|}{187 patients potentially eligible for MRI substudy } \\
\hline Reasons for further exclusion & pACC & Cerebellum \\
\hline $\begin{array}{l}\text { Missing, incomplete or } \\
\text { pathological psychometric } \\
\text { documentation }\end{array}$ & 8 & 8 \\
\hline $\begin{array}{l}\text { Study participation canceled or } \\
\text { consent withdrawal or non- } \\
\text { compliance* }\end{array}$ & 14 & 14 \\
\hline Metal implant & 8 & 8 \\
\hline Claustrophobia & 9 & 9 \\
\hline Abortion of measurement & 5 & 5 \\
\hline Different voxel position & 0 & 12 \\
\hline $\begin{array}{l}\text { Failure in measurement protocol, } \\
\text { data transfer, or data analysis }\end{array}$ & 12 & 11 \\
\hline Bad spectral quality & 8 & 6 \\
\hline New diagnosis of neurocytoma & 1 & 1 \\
\hline $\begin{array}{l}\text { Post hoc information about } \\
\text { exclusion criteria }\end{array}$ & 9 & 9 \\
\hline \multicolumn{3}{|c|}{$\begin{array}{l}113 \text { high quality pACC ( } 57 \mathrm{mADHD}: 56 \mathrm{fADHD} \text { ) and } 104 \text { cerebellar } \\
\text { spectra ( } 52 \text { mADHD:52 fADHD) }\end{array}$} \\
\hline $\begin{array}{l}\text { Exclusion due to not fulfilling } \\
\text { matching criteria }\end{array}$ & $\begin{array}{l}17(9 \\
\text { mADHD:8 } \\
\text { fADHD) }\end{array}$ & $\begin{array}{l}20(10 \\
\text { mADHD:10 } \\
\text { fADHD) }\end{array}$ \\
\hline
\end{tabular}
(57 mADHD, 56 fADHD) for pACC voxels and in 104 patients (52 mADHD, 52 fADHD) for the cerebellar location (Tables 1 and 2; cf. [15]).

\section{Matching procedures}

The pACC voxels of $57 \mathrm{mADHD}$ and 56 fADHD patients and the cerebellar voxels of $52 \mathrm{mADHD}$ and 52 fADHD patients were automatically matched according
Table 2 Recruitment process and reasons for exclusion (according to [15])

96 spectra (48 mADHD:48 fADHD) for pACC region and 84 (42 mADHD: $42 \mathrm{fADHD}$ ) for cerebellar region

Abbreviations: $p A C C$ pregenual anterior cingulate cortex, $m A D H D$ adult male ADHD patients, $f A D H D$ adult female ADHD patients

*Not showing up at the measurement dates

to age and premorbid verbal intelligence. We took a multidimensional matching approach using in-house software [16, 30, 55, 57]. For optimal matching, only age differences \pm 5 years and IQ differences \pm 10 points were tolerated between individual pairs. This resulted in an optimal matching for 48 (pACC) and 42 (cerebellum) male/female pairs (Table 3 ).

\section{MRI data acquisition}

All MR measurements were performed in the Department of Radiology at the University Medical Center Freiburg on a 3 Tesla whole-body scanner (Siemens Magnetom Trio, A TIM system; Erlangen, Germany) using a 12-channel head coil for signal reception. First, a T1-weighted 3D dataset was recorded using a magnetization-prepared rapid acquisition gradient echo with the following parameters: field of view $=256 \times 256 \mathrm{~mm}^{2}$, repetition time $(\mathrm{TR})=2200 \mathrm{~ms}$, echo time $(\mathrm{TE})=4.11 \mathrm{~ms}$, flip angle $=12^{\circ}$, voxel size $=1 \times$ $1 \times 1 \mathrm{~mm}^{3}$. For spectroscopic measurements, the voxels were placed in the pACC $(16 \times 25 \times 20 \mathrm{~mm})$ and in the center of the left cerebellar hemisphere $(20 \times 20 \times 20 \mathrm{~mm})$ 
Table 3 Demographic and psychometric data

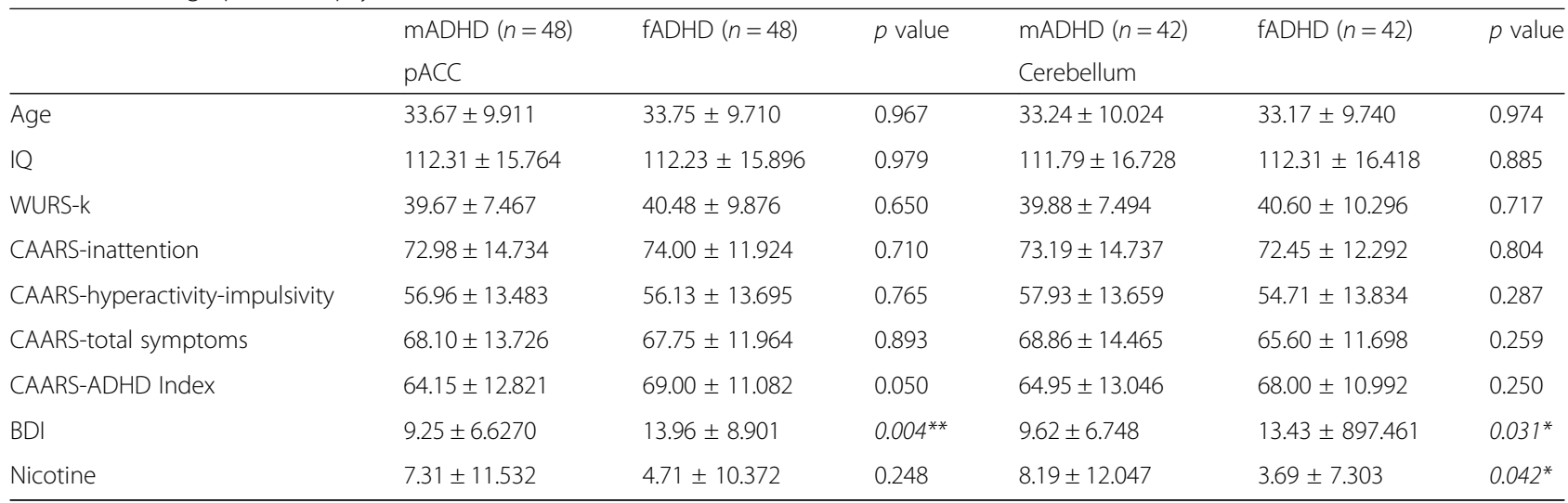

Abbreviations: IQ intelligence quotient (measured by the MWTB Multiple-Choice Vocabulary Intelligence Test), $m A D H D$ adult male ADHD patients, fADHD adult female ADHD patients, WURS-k Wender Utah Rating Scale, CAARS-S:L Conners Adult ADHD Rating Scales-Self Report: Long Version, BDI Beck Depression Inventory, nicotine nicotine consumption in cigarettes per day. For reference see text

${ }^{*} p<0.05,{ }^{* *} p<0.01$

(Fig. 1). The voxel in the ACC was placed centrally in front of the pregenual corpus callosum. The alignment in the transversal plane was done according to the anterior commissure/posterior commissure line. The voxel in the cerebellum was placed laterally to the vermis cerebelli in the left hemisphere. For MRS acquisition, a point-resolved spectroscopy (PRESS) sequence with a TR of $3000 \mathrm{~ms}$, a TE of $30 \mathrm{~ms}$, and 96 spectral averages was used for each person. For absolute quantification of the measured neurometabolites, we also

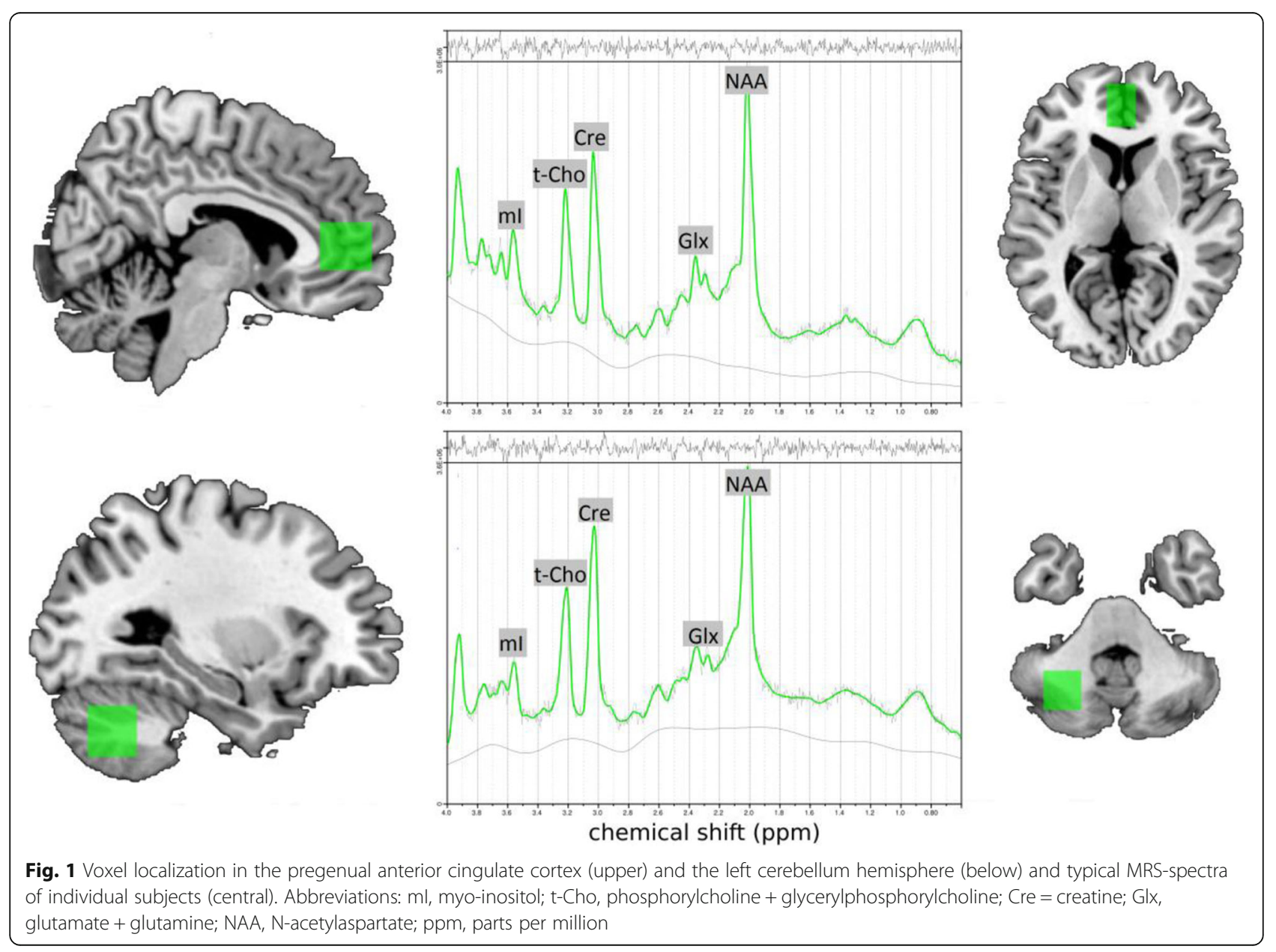


acquired a non-water-suppressed reference spectrum using the same sequence parameters.

\section{Spectroscopic analysis}

The spectroscopic analysis was conducted as described in earlier studies [15-17, 55, 57]. We used the linear combination of model spectra (LCModel) algorithm to ensure investigator-independent spectral analysis [44, 45]. An internal water signal reference was used for absolute metabolite quantification [27]. In further analyses, only metabolites with Cramér-Rao lower bounds $<20 \%$ for the main metabolites were included (http://s-provencher.com/pub/LCModel/manual/manual.pdf). Each acquired MR spectrum was visually controlled for baseline, line shape, peaks, and plausibility. To estimate the content of gray matter (GM), white matter (WM), and cerebrospinal fluid (CSF) in the pACC/ cerebellar volume of interest (VOI), the voxel volume was segmented using the unified-segmentation approach according to Ashburner and Friston [3], based on SPM8 (Wellcome Trust Centre for Neuroimaging, Institute of Neurology, London, UK), which was implemented using Matlab 7.12.0 (R2011a, MathWorks Inc., Sherborn, MA). The partial volumes of GM, WM, and CSF were used to estimate the water content in the VOI, which was needed for absolute quantification and for correction of the metabolite concentrations, assuming that the measured brain metabolites were present only in GM and WM and not in CSF.

\section{Statistical analysis}

Group comparisons of the parametric variables (age, IQ, nicotine consumption, and psychometric scores) were performed using independent samples $t$ tests in SPSS. The $\mathrm{mADHD}$ and fADHD groups were compared using a high-breakdown and high-efficiency robust linear regression [35] using the Robust package (https://CRAN. $\mathrm{R}$-project.org/package=robust) in R (https://www.R-project.org/). The level of significance was corrected for multiple testing using the Benjamini-Hochberg approach [5]. The level of significance was chosen as $p<0.05$. Correlation analyses were performed with SPSS using Pearson's correlation coefficient to assess a possible dimensional relationship between the neurometabolites of interest and the three most important ADHD/depression questionnaire scores (WURS-k, CAARS, BDI). Here, the level of significance was chosen as $p<0.008$ (two regions, three questionnaires) after Bonferroni correction.

\section{Results}

Demographic and psychometric data

The ages and IQs of the male and female ADHD patients did not differ significantly, given the automatic matching procedure. The psychometric scores for
ADHD symptoms (i.e., the WURS-k scores and the CAARS sub-scores for inattention, hyperactivityimpulsivity, total symptoms, or ADHD index) also did not differ significantly between the mADHD and fADHD groups. The nicotine consumption factor was balanced for the pACC data but not for the cerebellar data (and had no interaction with neurometabolite levels). The BDI score for depressiveness differed between male and female patients, in that females displayed higher BDI scores.

\section{MRS results}

Table 4 summarizes the spectroscopic results. Figure 2 shows the $\mathrm{t}$-Cho alterations as scatter plots. Dimensional analyses are shown in Tables 5 and 6.

\section{pACC}

The signals of Cre $(p=0.008)$ and $\mathrm{t}$-Cho $(p=0.004)$ showed a significant effect of the age covariate as well as an interaction of sex and age (Cre: $p=0.033$; $\mathrm{t}$-Cho: $p=$ 0.040). For the Glx signal, an interaction of sex and age could also be observed $(p=0.033)$. The correlation analysis did not reveal significant results after Bonferroni correction, but there was a trend for a positive correlation between the $\mathrm{mI}$ signal and the WURS score in $\mathrm{mADHD}$ and for a negative correlation between the $\mathrm{t}$ Cho concentration and the BDI score in fADHD.

\section{Cerebellum}

The signals of $\mathrm{t}$-Cho $(p=0.049)$ and Glx $(p=0.049)$ showed significant effects of the factor of sex. There were no effects of age, BDI, or sex and age. Again, no significant correlations could be discerned after correction for multiple testing, but there were trends for a positive correlation between the NAA concentration and the CAARS sub-score for hyperactivity-impulsivity in $\mathrm{MADHD}$ and for a positive correlation between the Glx signal and the CAARS sub-score for inattention in fADHD.

\section{Discussion}

The main findings of this study are neurometabolic sex differences in the pACC and left cerebellum in wellmatched groups of adult patients with mADHD and fADHD. At the level of single neurometabolites, there was evidence of age-dependent sex differences in the Cre, t-Cho, and Glx levels in pACC and ageindependent differences in the t-Cho and Glx levels in the cerebellum. One earlier study of children with ADHD described sex-dependent differences in the NAA signal. In our study of adult patients with ADHD, this could not be replicated. 
Table 4 Spectroscopic findings in the pACC and the cerebellum

\begin{tabular}{|c|c|c|c|c|c|c|}
\hline & $\begin{array}{l}\text { mADHD } \\
(n=48)\end{array}$ & $\mathrm{fADHD}(n=48)$ & Robust linear regression & $\begin{array}{l}\text { mADHD } \\
(n=42)\end{array}$ & $\mathrm{fADHD}(n=42)$ & Robust linear regression \\
\hline & pACC & & & Cerebellum & & \\
\hline Cre & $8.8544 \pm 1.16232$ & $8.9506 \pm 1.31720$ & $\begin{array}{l}\text { Sex: } F=0.017 \\
p=0.894, p_{\text {corr }}=0.894\end{array}$ & $9.3584 \pm 1.01449$ & $9.1434 \pm 1.30337$ & $\begin{array}{l}\text { Sex: } F=2.39 \\
p=0.115, p_{\text {corr }}=0.191\end{array}$ \\
\hline & & & $\begin{array}{l}\text { Age: } F=8.305 \text {, } \\
p=0.003^{*}, \boldsymbol{p}_{\text {corr }}=\mathbf{0 . 0 0 8}^{*}\end{array}$ & & & $\begin{array}{l}\text { Age: } F=0.237 \\
p=0.620, p_{\text {corr }}=0.775\end{array}$ \\
\hline & & & $\begin{array}{l}\mathrm{BDI}: \mathrm{F}=0.851 \\
p=0.347, p_{\text {corr }}=0.382\end{array}$ & & & $\begin{array}{l}\text { BDI: } F=0.914 \\
p=0.330, p_{\text {corr }}=0.575\end{array}$ \\
\hline & & & $\begin{array}{l}\text { Sex:age: } F=6.736, \\
p=0.008^{*}, \mathbf{p}_{\text {corr }}=\mathbf{0 . 0 3 3 ^ { * }}\end{array}$ & & & $\begin{array}{l}\text { Sex: age: } F=1.382 \\
p=0.231, p_{\text {corr }}=0.438\end{array}$ \\
\hline t-Cho & $2.3481 \pm .33682$ & $2.1581 \pm .42736$ & $\begin{array}{l}\text { Sex: } F=4.869, \\
p=0.025^{*}, p_{\text {corr }}=0.123\end{array}$ & $2.3634 \pm 0.32890$ & $2.2010 \pm 0.35128$ & $\begin{array}{l}\text { Sex: } F=6.054, \\
p=0.012^{*}, \boldsymbol{p}_{\text {corr }}=\mathbf{0 . 0 4 9 ^ { * }}\end{array}$ \\
\hline & & & $\begin{array}{l}\text { Age: } F=11.022 \\
p<0.001^{*}, \boldsymbol{p}_{\text {corr }}=\mathbf{0 . 0 0 4}^{*}\end{array}$ & & & $\begin{array}{l}\text { Age: } F=2.818 \\
p=0.087, p_{\text {corr }}=0.159\end{array}$ \\
\hline & & & $\begin{array}{l}\text { BDI: } F=4.278, \\
p=0.035^{*}, p_{\text {corr }}=0.175\end{array}$ & & & $\begin{array}{l}\text { BDI: } F=1.079 \\
p=0.290, p_{\text {corr }}=0.575\end{array}$ \\
\hline & & & $\begin{array}{l}\text { Sex:age: } F=4.921 \\
p=0.024^{*}, \boldsymbol{p}_{\text {corr }}=\mathbf{0 . 0 4 0}^{*}\end{array}$ & & & $\begin{array}{l}\text { Sex:age: } F=1.021 \\
p=0.303, p_{\text {corr }}=0.438\end{array}$ \\
\hline Glx & $16.1562 \pm 2.39563$ & $16.1508 \pm 2.49773$ & $\begin{array}{l}\text { Sex: } F=0.486 \\
p=0.477, p_{\text {corr }}=0.894\end{array}$ & $11.1479 \pm 1.51264$ & $10.4854 \pm 2.11368$ & $\begin{array}{l}\text { Sex: } F=5.242, \\
p=0.020^{*}, \boldsymbol{p}_{\text {corr }}=\mathbf{0 . 0 4 9 *}\end{array}$ \\
\hline & & & $\begin{array}{l}\text { Age: } F=0.019 \\
p=0.888, p_{\text {corr }}=0.888\end{array}$ & & & $\begin{array}{l}\text { Age: } F=3.005 \\
p=0.077, p_{\text {corr }}=0.159\end{array}$ \\
\hline & & & $\begin{array}{l}\text { BDI: } F=0.736 \\
p=0.382, p_{\text {corr }}=0.382\end{array}$ & & & $\begin{array}{l}\text { BDI: } F=0.303 \\
p=0.575, p_{\text {corr }}=0.575\end{array}$ \\
\hline & & & $\begin{array}{l}\text { Sex:age: } F=5.933, \\
p=0.013^{*}, \boldsymbol{p}_{\text {corr }}=\mathbf{0 . 0 3 3}^{*}\end{array}$ & & & $\begin{array}{l}\text { Sex:age: } F=0.556 \\
p=0.448, p_{\text {corr }}=0.448\end{array}$ \\
\hline NAA & $11.2331 \pm 1.82291$ & $11.6514 \pm 1.25699$ & $\begin{array}{l}\text { Sex: } F=0.361 \\
p=0.541, p_{\text {corr }}=0.894\end{array}$ & $8.9707 \pm 0.98168$ & $9.0642 \pm 0.93218$ & $\begin{array}{l}\text { Sex: } F=0.927 \\
p=0.327, p_{\text {corr }}=0.408\end{array}$ \\
\hline & & & $\begin{array}{l}\text { Age: } F=3.657 \\
p=0.051, p_{\text {corr }}=0.086\end{array}$ & & & $\begin{array}{l}\text { Age: } F=0.016 \\
p=0.897, p_{\text {corr }}=0.897\end{array}$ \\
\hline & & & $\begin{array}{l}\text { BDI: } F=0.835 \\
p=0.352, p_{\text {corr }}=0.382\end{array}$ & & & $\begin{array}{l}\mathrm{BDI}: \mathrm{F}=0.664 \\
p=0.406, p_{\text {corr }}=0.575\end{array}$ \\
\hline & & & $\begin{array}{l}\text { Sex:age: } F=3.629 \\
p=0.052, p_{\text {corr }}=0.065\end{array}$ & & & $\begin{array}{l}\text { Sex:age: } F=0.840 \\
p=0.350, p_{\text {corr }}=0.438\end{array}$ \\
\hline $\mathrm{ml}$ & $6.1587 \pm 0.96007$ & $6.1954 \pm 0.94481$ & $\begin{array}{l}\text { Sex: } F=0.031 \\
p=0.859, p_{\text {corr }}=0.894\end{array}$ & $4.8784 \pm 0.84957$ & $4.7396 \pm 0.82911$ & $\begin{array}{l}\text { Sex: } F=0.413 \\
p=0.513, p_{\text {corr }}=0.513\end{array}$ \\
\hline & & & $\begin{array}{l}\text { Age: } F=1.508 \\
p=0.211, p_{\text {corr }}=0.264\end{array}$ & & & $\begin{array}{l}\text { Age: } F=2.683 \\
p=0.095, p_{\text {corr }}=0.159\end{array}$ \\
\hline & & & $\begin{array}{l}\text { BDI: } F=2.931 \\
p=0.0811, p_{\text {corr }}=0.203\end{array}$ & & & $\begin{array}{l}\text { BDI: } F=0.439, \\
p=0.450, p_{\text {corr }}=0.575\end{array}$ \\
\hline & & & $\begin{array}{l}\text { Sex:age: } F=0.255 \\
p=0.607, p_{\text {corr }}=0.607\end{array}$ & & & $\begin{array}{l}\text { Sex:age: } F=1.334 \\
p=0.239, p_{\text {corr }}=0.438\end{array}$ \\
\hline
\end{tabular}

Abbreviations: $m A D H D$ male ADHD patients, $f A D H D$ female ADHD patients, $p A C C$ pregenual anterior cingulate cortex, $B D I$ Beck depression inventory, Cre creatine, $t$-Cho phosphorylcholine + glycerylphosphorylcholine, Glx glutamate + glutamine, NAA N-acetylaspartate, $\mathrm{ml}$ myo-inositol, $p$ corr corrected $p$ values using the Benjamini-Hochberg approach

*Significantly different (printed in bold)

\section{Previous studies}

In the only study analyzing sex effects in ADHD, lower NAA signals were found in the right frontal WM of female children [61]. Previous studies in healthy subjects reported mixed results in the ACC and cerebellum in comparisons of males and females (for a review, see [16]). In a previous study, applying the same method as used in the present one, balanced anterior cingulate neurometabolite signals were observed in a large sample of IQ- and age-matched healthy adults. In addition, significantly higher left cerebellar Cre and t-Cho signals and tendencies for higher Glx and $\mathrm{mI}$ concentrations were discerned in the male subgroup [16]. The agedependent anterior cingulate differences in metabolites detected in the current study are particularly striking with regard to ADHD, while we found cerebellar 


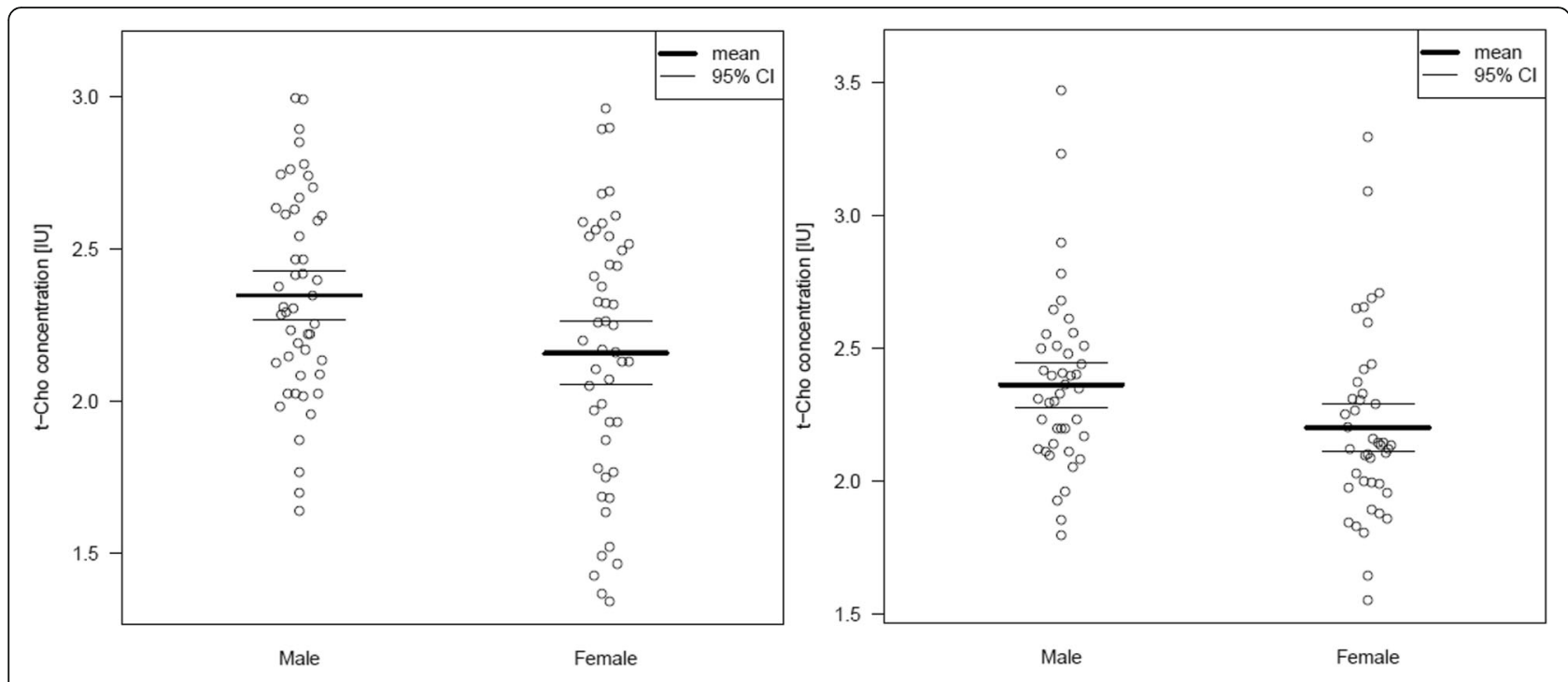

Fig. 2 Anterior cingulate (left) and left cerebellar (right) t-Cho concentration presented as scatterplots. Abbreviations: pACC, pregenual anterior cingulate cortex; IU, institutional unit; VOI, volume of interest; t-Cho, phosphorylcholine + glycerylphosphorylcholine

Table 5 Pearson correlation analyses in the male ADHD patient sample (level of significance $p<0.008$, pACC $n=48$, cerebellum $n=$ 42); presented are Pearson correlation coefficients and $p$ values

\begin{tabular}{|c|c|c|c|c|c|c|c|c|c|c|c|c|}
\hline & $\begin{array}{l}\text { WURS- } \\
k\end{array}$ & $\begin{array}{l}\text { CAARS- } \\
\text { inattention }\end{array}$ & $\begin{array}{l}\text { CAARS-hyper- } \\
\text { activity-im- } \\
\text { pulsivity }\end{array}$ & $\begin{array}{l}\text { CAARS-total } \\
\text { symptoms }\end{array}$ & $\begin{array}{l}\text { CAARS- } \\
\text { ADHD } \\
\text { Index }\end{array}$ & $\mathrm{BDI}$ & WURS-k & $\begin{array}{l}\text { CAARS- } \\
\text { inattention }\end{array}$ & $\begin{array}{l}\text { CAARS-hyper- } \\
\text { activity- } \\
\text { impulsivity }\end{array}$ & $\begin{array}{l}\text { CAARS-total- } \\
\text { symp-toms }\end{array}$ & $\begin{array}{l}\text { CAARS- } \\
\text { ADHD } \\
\text { Index }\end{array}$ & $\mathrm{BDI}$ \\
\hline & \multicolumn{6}{|c|}{ mADHD-pACC } & \multicolumn{6}{|c|}{ mADHD-cerebellum } \\
\hline \multirow[t]{2}{*}{ Cre } & $\begin{array}{l}r= \\
0.186\end{array}$ & $r=0.008$ & $r=-0.118$ & $r=-0.082$ & $\begin{array}{l}r=- \\
0.027\end{array}$ & $\begin{array}{l}r=- \\
0.157\end{array}$ & $\begin{array}{l}r=- \\
0.087\end{array}$ & $r=0.298$ & $r=0.119$ & $r=0.269$ & $r=0.010$ & $r=0.041$ \\
\hline & $\begin{array}{l}p= \\
0.205\end{array}$ & $p=0.957$ & $p=0.424$ & $p=0.578$ & $\begin{array}{l}p= \\
0.854\end{array}$ & $\begin{array}{l}p= \\
0.288\end{array}$ & $\begin{array}{l}p= \\
0.584\end{array}$ & $p=0.055$ & $p=0.452$ & $p=0.085$ & $\begin{array}{l}p= \\
0.948\end{array}$ & $\begin{array}{l}p= \\
0.796\end{array}$ \\
\hline \multirow[t]{2}{*}{$\begin{array}{l}\text { t- } \\
\text { Cho }\end{array}$} & $\begin{array}{l}r= \\
0.216\end{array}$ & $r=0.044$ & $r=-0.049$ & $r=0.009$ & $r=0.046$ & $\begin{array}{l}r= \\
-0.199\end{array}$ & $\begin{array}{l}r=- \\
0.012\end{array}$ & $r=0.238$ & $r=0.159$ & $r=0.248$ & $r=0.072$ & $r=0.026$ \\
\hline & $\begin{array}{l}p= \\
0.140\end{array}$ & $p=0.764$ & $p=0.743$ & $p=0.954$ & $\begin{array}{l}p= \\
0.755\end{array}$ & $\begin{array}{l}p= \\
0.176\end{array}$ & $\begin{array}{l}p= \\
0.940\end{array}$ & $p=0.129$ & $p=0.315$ & $p=0.113$ & $\begin{array}{l}p= \\
0.649\end{array}$ & $\begin{array}{l}p= \\
0.868\end{array}$ \\
\hline \multirow[t]{2}{*}{ Glx } & $\begin{array}{l}r= \\
0.130\end{array}$ & $r=0.099$ & $r=-0.128$ & $r=-0.011$ & $\begin{array}{l}r=- \\
0.043\end{array}$ & $\begin{array}{l}r=- \\
0.104\end{array}$ & $r=0.085$ & $r=-0.112$ & $r=-0.109$ & $r=-0.104$ & $\begin{array}{l}r=- \\
0.126\end{array}$ & $r=0.111$ \\
\hline & $\begin{array}{l}p= \\
0.377\end{array}$ & $p=0.503$ & $p=0.388$ & $p=0.941$ & $\begin{array}{l}p= \\
0.772\end{array}$ & $\begin{array}{l}p= \\
0.480\end{array}$ & $\begin{array}{l}p= \\
0.593\end{array}$ & $p=0.481$ & $p=0.493$ & $p=0.510$ & $\begin{array}{l}p= \\
0.427\end{array}$ & $\begin{array}{l}p= \\
0.486\end{array}$ \\
\hline \multirow[t]{2}{*}{ NAA } & $\begin{array}{l}r= \\
0.097\end{array}$ & $r=0.098$ & $r=0.043$ & $r=0.101$ & $r=0.102$ & $\begin{array}{l}r=- \\
0.230\end{array}$ & $\begin{array}{l}r=- \\
0.018\end{array}$ & $r=0.100$ & $r=0.367$ & $r=0.285$ & $r=0.146$ & $r=0.010$ \\
\hline & $\begin{array}{l}p= \\
0.512\end{array}$ & $p=0.506$ & $p=0.769$ & $p=0.493$ & $\begin{array}{l}p= \\
0.488\end{array}$ & $\begin{array}{l}p= \\
0.117\end{array}$ & $\begin{array}{l}p= \\
0.912\end{array}$ & $p=0.529$ & $p=0.017$ & $p=0.067$ & $\begin{array}{l}p= \\
0.356\end{array}$ & $\begin{array}{l}p= \\
0.952\end{array}$ \\
\hline \multirow[t]{2}{*}{$\mathrm{ml}$} & $\begin{array}{l}r= \\
0.315\end{array}$ & $r=-0.067$ & $r=-0.074$ & $r=-0.105$ & $r=0.005$ & $\begin{array}{l}r=- \\
0.180\end{array}$ & $r=0.031$ & $r=0.134$ & $r=0.115$ & $r=0.180$ & $\begin{array}{l}r=- \\
0.097\end{array}$ & $\begin{array}{l}r=- \\
0.091\end{array}$ \\
\hline & $\begin{array}{l}p= \\
0.029\end{array}$ & $p=0.650$ & $p=0.618$ & $p=0.479$ & $\begin{array}{l}p= \\
0.970\end{array}$ & $\begin{array}{l}p= \\
0.221\end{array}$ & $\begin{array}{l}p= \\
0.844\end{array}$ & $p=0.397$ & $p=0.469$ & $p=0.255$ & $\begin{array}{l}p= \\
0.543\end{array}$ & $\begin{array}{l}p= \\
0.566\end{array}$ \\
\hline
\end{tabular}

Abbreviations: $m A D H D$ male ADHD patients, pACC pregenual anterior cingulate cortex, WURS-k Wender Utah Rating Scale, CAARS-S:L Conners Adult ADHD Rating Scales-Self Report: Long Version, $B D I$ Beck Depression Inventory, Cre creatine, $t$-Cho phosphorylcholine + glycerylphosphorylcholine, Glx glutamate + glutamine, $N A A \mathrm{~N}$-acetylaspartate, $\mathrm{ml}$ myo-inositol. For reference, see text. Italicized data denote nominally significant at $p \leq 0.05$ 
Table 6 Pearson correlation analyses in the female ADHD patient sample (level of significance $p<0.008$, pACC $n=48$, cerebellum $n=42$ ). Presented are Pearson correlation coefficients and $p$ values

\begin{tabular}{|c|c|c|c|c|c|c|c|c|c|c|c|c|}
\hline & $\begin{array}{l}\text { WURS- } \\
k\end{array}$ & $\begin{array}{l}\text { CAARS- } \\
\text { inattention }\end{array}$ & $\begin{array}{l}\text { CAARS-hyper- } \\
\text { activity- } \\
\text { impulsivity }\end{array}$ & $\begin{array}{l}\text { CAARS-total- } \\
\text { symp-toms }\end{array}$ & $\begin{array}{l}\text { CAARS-ADHD } \\
\text { Index }\end{array}$ & $\mathrm{BDI}$ & $\begin{array}{l}\text { WURS- } \\
k\end{array}$ & $\begin{array}{l}\text { CAARS- } \\
\text { inattention }\end{array}$ & $\begin{array}{l}\text { CAARS-hyper- } \\
\text { activity- } \\
\text { impulsivity }\end{array}$ & $\begin{array}{l}\text { CAARS-total } \\
\text { symptoms }\end{array}$ & $\begin{array}{l}\text { CAARS- } \\
\text { ADHD } \\
\text { Index }\end{array}$ & $\mathrm{BDI}$ \\
\hline & \multicolumn{6}{|c|}{ fADHD - pACC } & \multicolumn{6}{|c|}{ fADHD-cerebellum } \\
\hline \multirow[t]{2}{*}{ Cre } & $\begin{array}{l}r=- \\
0.159\end{array}$ & $r=-0.021$ & $r=0.065$ & $r=0.030$ & $r=0.108$ & $\begin{array}{l}r=- \\
0.149\end{array}$ & $\begin{array}{l}r=- \\
0.082\end{array}$ & $r=0.123$ & $r=0.132$ & $r=0.166$ & $\begin{array}{l}r= \\
0.049\end{array}$ & $\begin{array}{l}r=- \\
0.252\end{array}$ \\
\hline & $\begin{array}{l}p= \\
0.281\end{array}$ & $p=0.887$ & $p=0.659$ & $p=0.840$ & $p=0.465$ & $\begin{array}{l}p= \\
0.313\end{array}$ & $\begin{array}{l}p= \\
0.604\end{array}$ & $p=0.437$ & $p=0.404$ & $p=0.293$ & $\begin{array}{l}p= \\
0.757\end{array}$ & $\begin{array}{l}p= \\
0.107\end{array}$ \\
\hline \multirow[t]{2}{*}{$\begin{array}{l}\text { t- } \\
\text { Cho }\end{array}$} & $\begin{array}{l}r=- \\
0.152\end{array}$ & $r=-0.162$ & $r=0.067$ & $r=-0.059$ & $r=-0.090$ & $\begin{array}{l}r=- \\
0.341\end{array}$ & $\begin{array}{l}r=- \\
0.060\end{array}$ & $r=0.063$ & $r=0.068$ & $r=0.110$ & $\begin{array}{l}r= \\
0.046\end{array}$ & $\begin{array}{l}r=- \\
0.199\end{array}$ \\
\hline & $\begin{array}{l}p= \\
0.301\end{array}$ & $p=0.271$ & $p=0.649$ & $p=0.691$ & $p=0.541$ & $\begin{array}{l}p= \\
0.018\end{array}$ & $\begin{array}{l}p= \\
0.704\end{array}$ & $p=0.692$ & $p=0.668$ & $p=0.486$ & $\begin{array}{l}p= \\
0.773\end{array}$ & $\begin{array}{l}p= \\
0.206\end{array}$ \\
\hline \multirow[t]{2}{*}{ Glx } & $\begin{array}{l}r=- \\
0.026\end{array}$ & $r=-0.112$ & $r=0.154$ & $r=0.037$ & $r=0.063$ & $\begin{array}{l}r=- \\
0.132\end{array}$ & $\begin{array}{l}r= \\
0.125\end{array}$ & $r=0.375$ & $r=0.080$ & $r=0.274$ & $\begin{array}{l}r= \\
0.240\end{array}$ & $\begin{array}{l}r= \\
0.020\end{array}$ \\
\hline & $\begin{array}{l}p= \\
0.859\end{array}$ & $p=0.449$ & $p=0.296$ & $p=0.803$ & $p=0.670$ & $\begin{array}{l}p= \\
0.369\end{array}$ & $\begin{array}{l}p= \\
0.432\end{array}$ & $p=0.014$ & $p=0.614$ & $p=0.079$ & $\begin{array}{l}p= \\
0.126\end{array}$ & $\begin{array}{l}p= \\
0.900\end{array}$ \\
\hline \multirow[t]{2}{*}{ NAA } & $\begin{array}{l}r= \\
-0.180\end{array}$ & $r=0.022$ & $r=-0.016$ & $r=-0.016$ & $r=0.123$ & $\begin{array}{l}r=- \\
0.128\end{array}$ & $\begin{array}{l}r=- \\
0.213\end{array}$ & $r=-0.047$ & $r=0.046$ & $r=0.038$ & $\begin{array}{l}r= \\
0.103\end{array}$ & $\begin{array}{l}r=- \\
0.247\end{array}$ \\
\hline & $\begin{array}{l}p= \\
0.220\end{array}$ & $p=0.881$ & $p=0.914$ & $p=0.916$ & $p=0.404$ & $\begin{array}{l}p= \\
0.386\end{array}$ & $\begin{array}{l}p= \\
0.175\end{array}$ & $p=0.768$ & $p=0.774$ & $p=0.812$ & $\begin{array}{l}p= \\
0.518\end{array}$ & $\begin{array}{l}p= \\
0.115\end{array}$ \\
\hline \multirow[t]{2}{*}{$\mathrm{ml}$} & $\begin{array}{l}r=- \\
0.254\end{array}$ & $r=-0.139$ & $r=-0.199$ & $r=-0.180$ & $r=-0.157$ & $\begin{array}{l}r=- \\
0.206\end{array}$ & $\begin{array}{l}r=- \\
0.020\end{array}$ & $r=0.236$ & $r=0.028$ & $r=0.168$ & $\begin{array}{l}r= \\
0.074\end{array}$ & $\begin{array}{l}r= \\
0.025\end{array}$ \\
\hline & $\begin{array}{l}p= \\
0.081\end{array}$ & $p=0.344$ & $p=0.175$ & $p=0.221$ & $p=0.288$ & $\begin{array}{l}p= \\
0.160\end{array}$ & $\begin{array}{l}p= \\
0.898\end{array}$ & $p=0.133$ & $p=0.860$ & $p=0.289$ & $\begin{array}{l}p= \\
0.640\end{array}$ & $\begin{array}{l}p= \\
0.874\end{array}$ \\
\hline
\end{tabular}

Abbreviations: $f A D H D$ female ADHD patients, $p A C C$ pregenual anterior cingulate cortex, WURS-k Wender Utah Rating Scale, CAARS-S:L Conners Adult ADHD Rating Scales-Self Report: Long Version, $B D I$ Beck Depression Inventory, Cre creatine, $t$-Cho phosphorylcholine + glycerylphosphorylcholine, Glx glutamate + glutamine, $N A A \mathrm{~N}$-acetylaspartate, $\mathrm{ml}$ myo-inositol. For reference see text. Italicized data denote nominally significant at $p<0.05$

alterations in t-Cho and tendentially for Glx earlier in healthy individuals.

\section{Neurochemical perspective}

Higher t-Cho levels might be attributed to demyelination [25] or increased membrane biosynthesis (i.e., myelination) [10]. Myelination is prompted by oligodendrocytes during the first four decades of life [4, 52]. Therefore, different age-dependent anterior cingulate $\mathrm{t}$-Cho signals might indicate a disturbed myelinization in mADHD. As demonstrated in previous structural imaging studies, there is a delay in cortical maturation in ADHD, with patients showing diverse growth curves [53, 54]. The delayed cortical maturation in mADHD might explain the decline of symptoms in some adults with ADHD compared to children with this disorder. In childhood, ADHD is diagnosed more frequently in boys than in girls, with a 4:1 ratio of mADHD:fADHD. In contrast, sex ratios are almost balanced in adult ADHD [58]. In turn, different $\mathrm{t}$-Cho and other neurometabolite levels might be explained by hormonal influences. In a previous study in female subjects, $\mathrm{t}$-Cho/Cre signals in the parietal region differed significantly between the midfollicular and the late luteal phase of the menstrual cycle
[46]. NAA/Cre ratios were also dependent on the cycle phase [46].

\section{Clinical perspective}

The clinical role of sex differences in ADHD was first discussed in a conference on sex differences over 20 years ago [2]. Several papers about sex differences in ADHD have been published since then [e.g., 7, 12, 21, $22,60]$. The first two clinical studies found lower levels of hyperactivity and lower rates of other externalizing behaviors in fADHD [21, 22]. Furthermore, greater levels of intellectual impairment [21] and lower levels of inattention and impulsivity [22] have been reported in fADHD. Robinson et al. observed higher depression scores, more sleep problems, and higher levels of emotional dysregulation in adult fADHD as compared to mADHD [49]. Other studies of adult ADHD have suggested similar patterns [51], while Grevet et al. failed to detect significant interactions between sex and ADHD subtypes [23]. However, comorbidity in ADHD differs according to sex, with mADHD patients suffering more frequently from an antisocial personality disorder, conduct disorder, and substance abuse, while, in fADHD patients, comorbidity with mood disorders, eating disorders, and sleep problems prevail [20]. 
Further studies are necessary to understand possibly underlying neurobiological processes.

\section{Relevance for further studies in ADHD}

Given the present findings and the converging body of evidence from the available literature, future studies in ADHD might profit in general from including balanced sex ratios, and/or the specific findings for each sex should be reported. Otherwise, data should be corrected for the sex factor. In female-only or mixed groups, studies should correct for the phases of the menstrual cycle and the use of hormonal contraceptives, as hormonal influences could have significant effects on neurometabolites.

\section{Limitations}

Patients were recruited from the COMPAS study $[15,24,34,39,41,43,56]$. These patients underwent an intensive screening process, and broad demographic, psychometric, and laboratory results were available. The inclusion and exclusion criteria are presented in Table 1. Only ADHD cases without other underlying organic diseases were included. Therefore, the present results cannot be generalized to secondary forms of ADHD. None of the patients had taken any ADHD-specific medication for at least 6 months prior to the study. Therefore, the possible short-term effects of medication could be excluded. However, the effects of earlier medication on neurometabolism could not be evaluated, especially if one assumes that mADHD patients may have been treated more frequently with stimulants earlier. The results of the main MRS study comparing ADHD patients with healthy controls have been published elsewhere [15]. Briefly, those results were mostly negative, with balanced sex ratios [15] and no differences in the concentrations of the principal metabolites (Cre, tCho, Glx, NAA, mI). As shown in earlier investigations, age [29], IQ [28], and nicotine consumption [13, 33] may influence MRS results. Therefore, in the present study, the mADHD and fADHD groups were matched for age and IQ. Nicotine consumption had no significant interaction with neurometabolite concentrations. We were not able to correct for the menstrual cycle in this study; future studies should pay attention to this.

On a technical level, we used SVS, which is a wellestablished method. Data analysis was performed with the investigator-independent LCModel algorithm. Also, for the absolute quantification of the neurometabolites, an established method was applied [15-17, 55, 57]. The metabolite concentration of each VOI was corrected according to the partial volumes of GM, WM, and CSF. In order to keep the MRI duration short, only two brain regions (i.e., the pACC and left cerebellum) were analyzed, not allowing for generalization to other brain regions.

\section{Conclusion}

This is the largest study to date analyzing sex differences in brain neurochemistry for the first time in adult ADHD. Significant neurometabolic sex differences were identified in the pACC (age-dependent) and the left cerebellum. Further MRS studies of sex differences in ADHD patients that also investigate other relevant brain areas, include balanced sex ratios, and control for the menstrual cycle phase are warranted to validate the present findings.

\section{Acknowledgements}

We would like to thank all patients for participating in the study. DE was supported by the Berta-Ottenstein-Programme for Advanced Clinician Scientists, Faculty of Medicine, University of Freiburg.

\section{Authors' contributions}

$D E, L T V E$, and EP initiated the study. DE and EP conducted the data analysis. SM performed the statistical analyses. DE wrote the paper; he was supported by KN and EP. BF and TL gave technical support. DE, LTVE, SJM, PG, SAM, SM, $E S, A P, K N$, and $E P$ were involved in patient recruitment or $M R$ measurements. KD critically revised the manuscript. All authors were crucially involved in the theoretical discussion and performing of the manuscript. All authors read and approved the final version of the manuscript.

\section{Funding}

The study was funded by the German Federal Ministry of Science and Education (ADHD-NET 01GV0605, 01GV0606). The article processing charge was funded by the German Research Foundation (DFG) and the University of Freiburg in the funding program Open Access Publishing.

\section{Availability of data and materials \\ Not applicable.}

\section{Ethics approval and consent to participate}

Approval from the local ethics committee was obtained (Faculty of Medicine, Freiburg University, 217/06). The study was registered by Current Controlled Trials (ISRCTN54096201) and was conducted according to the ethical principles of the Helsinki Declaration.

\section{Consent for publication}

Not applicable.

\section{Competing interests}

LTVE has served on advisory boards, given lectures, or received travel grants within the last 3 years from Eli Lilly, Janssen-Cilag, Novartis, Shire, UCB, GSK, Servier, Janssen, and Cyberonics. PG received travel grant from GSK, Boston Scientific, Otsuka Pharma, and Actelion. SM received a speaker's fee and was involved as a study physician in clinical trials conducted by Janssen-Cilag and Lilly from 2007 to 2009. She is currently involved in clinical trials conducted by Janssen and Lundbec. She has been a member of the advisory board of Shire Deutschland and Medice. AP has served on advisory boards, given lectures, performed phase 3 studies, or received travel grants within the last 3 years from Eli Lilly and Co, Janssen-Cilag, MEDICE Arzneimittel Putter GmbH and Co KG, Novartis, and Shire and has authored books and articles on psychotherapy published by Elsevier, Hogrefe, Schattauer, Kohlhammer, Karger, Springer, and Oxford University Press. All other authors, $D E, E P, K N, S J M, B F, S A M, K D, T L, E S$, declare that they have no competing interests.

\section{Author details}

${ }^{1}$ Section for Experimental Neuropsychiatry, Department of Psychiatry and Psychotherapy, Medical Center-University of Freiburg, Faculty of Medicine, University of Freiburg, Freiburg, Germany. ${ }^{2}$ Department of Psychiatry and Psychotherapy, Medical Center-University of Freiburg, Faculty of Medicine, University of Freiburg, Freiburg, Germany. ${ }^{3}$ Department of Radiology, Medical 
Physics, Medical Center-University of Freiburg, Faculty of Medicine, University of Freiburg, Freiburg, Germany. ${ }^{4}$ Department of Psychiatry and Psychotherapy, Central Institute of Mental Health, Clinical Faculty Mannheim, University of Heidelberg, Mannheim, Germany. ${ }^{5}$ Department of Child and Adolescent Psychiatry and Psychotherapy, University Medicine Mainz, Mainz, Germany. ${ }^{6}$ Department of Psychiatry and Psychotherapy, University of Bonn, Bonn, Germany. ${ }^{7}$ Clinic for Psychiatry Luzern, St. Urban, Switzerland.

\section{Received: 2 February 2019 Accepted: 30 August 2019}

Published online: 29 October 2019

\section{References}

1. Aoki $Y$, Inokuchi $R$, Suwa $H$, et al. Age-related change of neurochemical abnormality in attention-deficit hyperactivity disorder: a meta-analysis. Neurosci Biobehav Rev. 2013;37(8):1692-701.

2. Arnold LE. Sex differences in ADHD: conference summary. J Abnorm Child Psychol. 1996;24(5):555-69.

3. Ashburner J, Friston KJ. Unified segmentation. Neuroimage. 2005;26(3): 839-51.

4. Bartzokis G, Beckson M, Lu PH, et al. Age-related changes in frontal and temporal lobe volumes in men: a magnetic resonance imaging study. Arch Gen Psychiatry. 2001;58(5):461-5.

5. Benjamini $Y$, Hochberg Y. Controlling the false discovery rate: a practical and powerful approach to multiple testing. J R Stat Soc Ser B. 1995;57:289-300.

6. Biederman J, Faraone SV. Attention-deficit hyperactivity disorder. Lancet. 2005;366(9481):237-48

7. Biederman J, Kwon A, Aleardi M, et al. Absence of gender effects on attention deficit hyperactivity disorder: findings in nonreferred subjects. Am J Psychiatry. 2005;162(6):1083-9.

8. Carlsson A, Hansson LO, Waters N, et al. A glutamatergic deficiency model of schizophrenia. Br J Psychiatry Suppl. 1999a;37:2-6.

9. Carlsson A, Waters N, Carlsson ML. Neurotransmitter interactions in schizophrenia--therapeutic implications. Biol Psychiatry. 1999b;46(10): 1388-95.

10. Colla M, Ende G, Alm B, et al. Cognitive MR spectroscopy of anterior cingulate cortex in ADHD: elevated choline signal correlates with slowed hit reaction times. J Psychiatr Res. 2008;42(7):587-95.

11. Conners C, Erhardt D, Sparrow E. Conners' adult ADHD rating scales (CAAR S). North Tonawanda: Multi-Health Systems; 1999.

12. Davies W. Sex differences in attention deficit hyperactivity disorder: candidate genetic and endocrine mechanisms. Front Neuroendocrinol. 2014;35(3):331-46. https://doi.org/10.1016/j.yfrne.2014.03.003 Epub 2014 Mar 26. Review.

13. Domino EF. Tobacco smoking and MRI/MRS brain abnormalities compared to nonsmokers. Prog Neuro-Psychopharmacol Biol Psychiatry. 2008;32(8): 1778-81.

14. Ebert D, Krause J, Roth-Sackenheim C. ADHD in adulthood--guidelines based on expert consensus with DGPPN support. Nervenarzt. 2003;74(10): 939-46.

15. Endres D, Perlov E, Maier S, et al. Normal neurochemistry in the prefrontal and cerebellar brain of adults with attention-deficit-hyperactivity disorder. Front Behav Neurosci. 2015;9:242.

16. Endres $D$, Tebartz van Elst $L$, Feige $B$, et al. On the effect of sex on prefrontal and cerebellar Neurometabolites in healthy adults: an MRS study. Front Hum Neurosci. 2016;10:367.

17. Endres D, Tebartz van Elst L, Meyer SA, et al. Glutathione metabolism in the prefrontal brain of adults with high-functioning autism spectrum disorder: an MRS study. Mol Autism. 2017;8:10. https://doi.org/10.1186/s13229-0170122-3 eCollection 2017.

18. Fayyad J, Sampson NA, Hwang I, et al. The descriptive epidemiology of DSM-IV adult ADHD in the world health organization world mental health surveys. Atten Defic Hyperact Disord. 2017;9(1):47-65.

19. Cortese S, Coghill D. Twenty years of research on attention-deficit/ hyperactivity disorder (ADHD): looking back, looking forward. Evid Based Ment Health. 2018;21(4):173-6. https://doi.org/10.1136/ebmental-2018300050 Epub 2018 Oct 9. Review.

20. Fedele DA, Lefler EK, Hartung CM, et al. Sex differences in the manifestation of ADHD in emerging adults. J Atten Disord. 2012;16(2):109-17.

21. Gaub M, Carlson CL. Gender differences in ADHD: a meta-analysis and critical review. J Am Acad Child Adolesc Psychiatry. 1997;36(8):1036-45.
22. Gershon J. A meta-analytic review of gender differences in ADHD. J Atten Disord. 2002:5(3):143-54.

23. Grevet EH, Bau CHD, Salgado CAl, et al. Lack of gender effects on subtype outcomes in adults with attention-deficit/hyperactivity disorder: support for the validity of subtypes. Eur Arch Psychiatry Clin Neurosci. 2006;256(5):311-9.

24. Groß V, Lücke C, Graf E, et al. Comparison of methylphenidate and psychotherapy in adult ADHD study (COMPAS) consortium. Effectiveness of psychotherapy in adult ADHD: what do patients think? Results of the COMPAS study. J Atten Disord. 2017;1:1087054717720718. https://doi.org/10. 1177/1087054717720718 [Epub ahead of print].

25. Gujar SK, Maheshwari S, Björkman-Burtscher I, et al. Magnetic resonance spectroscopy. J Neuroophthalmol. 2005;25(3):217-26.

26. Hautzinger M (2006). Das Beck Depressionsinventar II. Deutsche Bearbeitung und Handbuch zum BDI II. Frankfurt a. M.: Harcourt Test Services.

27. Helms $G$. The principles of quantification applied to in vivo proton MR spectroscopy. Eur J Radiol. 2008;67(2):218-29.

28. Jung RE, Brooks WM, et al. Biochemical markers of intelligence: a proton MR spectroscopy study of normal human brain. Proc Biol Sci. 1999;266(1426):1375-9.

29. Kaiser LG, Schuff N, Cashdollar N, et al. Age-related glutamate and glutamine concentration changes in normal human brain: $1 \mathrm{H}$ MR spectroscopy study at 4 T. Neurobiol Aging. 2005;26(5):665-72.

30. Kaller CP, Loosli SV, Rahm B, Gössel A, Schieting S, Hornig T, et al. Working memory in schizophrenia: behavioral and neural evidence for reduced susceptibility to itemspecific proactive interference. Biol Psychiatry. 2014;76(6):486-94.

31. Kooij JJS, Bijlenga D, Salerno L, et al. Updated European consensus statement on diagnosis and treatment of adult ADHD. Eur Psychiatry. 2018; 56:14-34. https://doi.org/10.1016/j.eurpsy.2018.11.001 [Epub ahead of print].

32. Lehrl S, Triebig G, Fischer B. Multiple choice vocabulary test MWT as a valid and short test to estimate premorbid intelligence. Acta Neurol Scand. 1995; 91(5):335-45.

33. Licata SC, Renshaw PF. Neurochemistry of drug action: insights from proton magnetic resonance spectroscopic imaging and their relevance to addiction. Ann N Y Acad Sci. 2010;1187:148-71.

34. Maier S, Perlov E, Graf E, et al. Discrete global but no focal gray matter volume reductions in unmedicated adult patients with attention-deficit/ hyperactivity disorder. Biol Psychiatry. 2016;80(12):905-15. https://doi.org/10. 1016/j.biopsych.2015.05.012 Epub 2015 May 27.

35. Maronna RA, Yohai VJ. Robust regression with both continuous and categorical predictors. J Statist Plann Inference. 2000;89:197-214.

36. Naaijen J, Bralten J, Poelmans G, et al. Glutamatergic and GABAergic gene sets in attention-deficit/hyperactivity disorder: association to overlapping traits in ADHD and autism. Transl Psychiatry. 2017;7(1):e999.

37. Perlov E, Philipsen A, Hesslinger B, et al. Reduced cingulate glutamate/ glutamine-to-creatine ratios in adult patients with attention deficit/ hyperactivity disorder - a magnet resonance spectroscopy study. J Psychiatr Res. 2007:41(11):934-41.

38. Perlov E, Philipsen A, Matthies S, et al. Spectroscopic findings in attentiondeficit/hyperactivity disorder: review and meta-analysis. World J Biol Psychiatry. 2009;10(4 Pt 2):355-65.

39. Philipsen A (2008). Prüfplan: Vergleich einer strukturierten störungsspezifischen Gruppenpsychotherapie plus Placebo oder Methylphenidat versus einer psychiatrischen Beratung plus Placebo oder Methylphenidat bei ADHS im Erwachsenenalter - eine erste randomisierte Multizenter-Studie (BMBF-ADHD-C1); Available from: URL:http://www. uniklinik-freiburg.de/fileadmin/mediapool/07_kliniken/psy_psychiatrie/pdf/ forschung/Pr\%C3\%BCfplan_Protokollversion_5_-Amendment-4_17.12.08.pdf.

40. Philipsen A, Graf E, Tebartz van Elst $L$, et al. Evaluation of the efficacy and effectiveness of a structured disorder tailored psychotherapy in ADHD in adults: study protocol of a randomized controlled multicentre trial. Atten Defic Hyperact Disord. 2010;2(4):203-12.

41. Philipsen A, Graf E, Jans T, et al. A randomized controlled multicenter trial on the multimodal treatment of adult attention-deficit hyperactivity disorder: enrollment and characteristics of the study sample. Atten Defic Hyperact Disord. 2014;6(1):35-47.

42. Philipsen A, Hesslinger B, Tebartz van Elst L. Attention deficit hyperactivity disorder in adulthood: diagnosis, etiology and therapy. Dtsch Arztebl Int. 2008;105(17):311-7.

43. Philipsen A, Jans T, Graf E, et al. Effects of group psychotherapy, individual counseling, methylphenidate, and placebo in the treatment of adult 
attention-deficit/hyperactivity disorder: a randomized clinical trial. JAMA Psychiat. 2015;72(12):1199-210

44. Provencher SW. Estimation of metabolite concentrations from localized in vivo proton NMR spectra. Magn Reson Med. 1993;30(6):672-9.

45. Provencher SW. Automatic quantitation of localized in vivo $1 \mathrm{H}$ spectra with LCModel. NMR Biomed. 2001;14(4):260-4.

46. Rasgon NL, Thomas MA, Guze BH, et al. Menstrual cycle-related brain metabolite changes using $1 \mathrm{H}$ magnetic resonance spectroscopy in premenopausal women: a pilot study. Psychiatry Res. 2001;106(1):47-57.

47. Retz-Junginger $P$, Retz W, Blocher D, et al. Wender Utah Rating Scale (WURS-k) Die deutsche Kurzform zur retrospektiven Erfassung des hyperkinetischen Syndroms bei Erwachsenen. Nervenarzt. 2002;73(9):830-8.

48. Retz-Junginger P, Sobanski E, Alm B, et al. Alters- und geschlechtsspezifische Besonderheiten der Aufmerksamkeitsdefizit-/Hyperaktivitätsstörung. Nervenarzt. 2008:79(7):809-19.

49. Robison RJ, Reimherr FW, Marchant BK, et al. Gender differences in 2 clinical trials of adults with attention-deficit/hyperactivity disorder: a retrospective data analysis. J Clin Psychiatry. 2008;69(2):213-21.

50. Ross B, Bluml S. Magnetic resonance spectroscopy of the human brain. Anat Rec. 2001;265(2):54-84.

51. Rucklidge JJ. Gender differences in attention-deficit/hyperactivity disorder. Psychiatr Clin North Am. 2010;33(2):357-73.

52. Russell VA, Oades RD, Tannock $R$ al. Response variability in attention-deficit/ hyperactivity disorder: a neuronal and glial energetics hypothesis. Behav Brain Funct. 2006;2:30.

53. Shaw P, Eckstrand K, Sharp W, et al. Attention-deficit/hyperactivity disorder is characterized by a delay in cortical maturation. Proc Natl Acad Sci U S A. 2007;104(49):19649-54.

54. Shaw P, Malek M, Watson B, et al. Development of cortical surface area and gyrification in attention-deficit/hyperactivity disorder. Biol Psychiatry. 2012;72(3):191-7.

55. Tebartz van Elst L, Maier S, Fangmeier T, et al. Disturbed cingulate glutamate metabolism in adults with high-functioning autism spectrum disorder: evidence in support of the excitatory/inhibitory imbalance hypothesis. Mol Psychiatry. 2014;19(12):1314-25.

56. Tebartz van Elst L, Maier S, Klöppel S, et al. The effect of methylphenidate intake on brain structure in adults with ADHD in a placebo-controlled randomized trial. J Psychiatry Neurosci. 2016;41(6):422-30.

57. van Elst LT, Maier S, Fangmeier T, et al. Magnetic resonance spectroscopy comparing adults with high functioning autism and above average IQ. Mol Psychiatry. 2014;19(12):1251.

58. Volkow ND, Swanson JM. Clinical practice: adult attention deficithyperactivity disorder. N Engl J Med. 2013;369(20):1935-44.

59. Ward MF, Wender PH, Reimherr FW. The Wender Utah Rating Scale: an aid in the retrospective diagnosis of childhood attention deficit hyperactivity disorder. Am J Psychiatry. 1993;150(6):885-90.

60. Williamson D, Johnston C. Gender differences in adults with attentiondeficit/hyperactivity disorder: a narrative review. Clin Psychol Rev. 2015; 40:15-27.

61. Yeo RA, Hill DE, Campbell RA, et al. Proton magnetic resonance spectroscopy investigation of the right frontal lobe in children with attention-deficit/hyperactivity disorder. J Am Acad Child Adolesc Psychiatry. 2003;42(3):303-10

\section{Publisher's Note}

Springer Nature remains neutral with regard to jurisdictional claims in published maps and institutional affiliations.

Ready to submit your research? Choose BMC and benefit from:
- fast, convenient online submission
- thorough peer review by experienced researchers in your field
- rapid publication on acceptance
- support for research data, including large and complex data types
- gold Open Access which fosters wider collaboration and increased citations
- maximum visibility for your research: over 100M website views per year
At BMC, research is always in progress.
Learn more biomedcentral.com/submissions

